\title{
Post-exertion dizziness as the sole presenting symptom of autonomic failure
}

\author{
G D P Smith, R Bannister, C J Mathias
}

\begin{abstract}
An otherwise fit young man, leading an active life, whose only complaint at presentation was dizziness after extreme exertion is described. He was found later to have postural and exercise induced hypotension. Subsequently, he developed typical symptoms of autonomic failure, with postural dizziness, urinary abnormalities, and erectile failure. Progression of autonomic failure was documented on testing. A fall in blood pressure during or after exercise has been reported previously in pure autonomic failure, but a presentation with exercise induced symptoms alone is unusual.
\end{abstract}

(Br Heart f 1993;69:359-361)

Hypotension with dizziness during exertion is a recognised presenting feature of ischaemic heart disease. ${ }^{12}$ It may also occur after extreme exertion in healthy young adults. ${ }^{34}$ We describe a man who presented with dizziness after extreme exertion and report our observations over a two year period.

\section{Case report}

A 40 year old man presented with intermittent episodes of dizziness associated with blurred vision. $\mathrm{He}$ was otherwise well. $\mathrm{He}$ played sport regularly and worked as a fireman. The first episode of dizziness occurred when he was 39 while he was walking on a hot day. Subsequent episodes only occurred after extreme exertion, for instance while playing badminton at which he was highly competent. The symptoms occurred at the end of exercise when he felt dizzy but did not lose consciousness. At presentation there was no history to suggest postural hypotension. Urinary bladder, large bowel, sexual, and sudomotor function were normal. He had no chest pain, palpitation, or dyspnoea. The only past medical history of note was poliomyelitis at the age of 12 , from which he recovered completely.

On clinical examination no abnormality was found. Investigations including routine blood tests, chest $x$ ray, 12 lead and 24 hour electrocardiograms, brain computed tomography scan, and intravenous digital subtraction angiography of the cerebral vessels were normal. No diagnosis was made and a functional component to his symptoms was considered. He continued to have symptoms but no abnormality was found on repeated clini- cal assessment. Eight months after his initial episode postural hypotension was noted and he was referred for autonomic assessment. Clinical examination again demonstrated no abnormality except for an asymptomatic postural fall in blood pressure, confirmed on formal autonomic testing, from $124 / 61 \mathrm{~mm} \mathrm{Hg}$ supine to $88 / 54 \mathrm{~mm} \mathrm{Hg}$ on standing and to $92 / 57 \mathrm{~mm} \mathrm{Hg}$ on $45^{\circ}$ tilt. There was no pressor response to cutaneous cold but responses to a range of autonomic tests designed to assess sympathetic and cardiac parasympathetic function were normal. These included mental arithmetic, isometric exercise, hyperventilation, the Valsalva manoeuvre and preserved sinus arrhythmia during deep breathing. The response to food ingestion, which can lower supine blood pressure and accentuate postural hypotension in some patients with autonomic failure, ${ }^{5}$ was normal. Because of the relation between his symptoms and exertion, we asked him to run up and down stairs. After this he felt dizzy and his standing blood pressure fell to $65 / 32 \mathrm{~mm}$ $\mathrm{Hg}$ with a heart rate of 114 beats/minute. $\mathrm{He}$ was therefore investigated further. Urea and electrolytes, full blood count, erythrocyte sedimentation rate, thyroid function tests, glucose, liver function tests, syphilis serology, and autoantibodies were all normal. The basal concentration of noradrenaline when he was supine was low $(0.725 \mathrm{nmol} / 1$; normal range 1.5 to $2.0 \mathrm{nmol} / \mathrm{l}$ ) with a modest rise with $45^{\circ}$ tilt to $1.38 \mathrm{nmol} / 1$ (normal range 2.5 to $3.0 \mathrm{nmol} / \mathrm{l}$ ). The concentration of plasma dopamine $\beta$ hydroxylase was low (18 $\mathrm{nmol} / \mathrm{ml} / 20 \mathrm{~min}$; normal $>100 \mathrm{nmol} / \mathrm{ml} / 20$ min), but unlike patients with dopamine $\beta$ hydroxylase deficiency ${ }^{6}$ he had a normal plasma dopamine concentration of $0.107 \mathrm{nmol} / 1$ (normal range $0 \cdot 1-0 \cdot 16 \mathrm{nmol} / \mathrm{l}$ ). A thermoregulatory sweat test indicated no sweating with a $1^{\circ}$ rise in body temperature. A phenylephrine eye test suggested adrenergic hypersensitivity in both pupils. Brain magnetic resonance imaging and positron emission tomography with 18-fluorodopa were normal. Because pure autonomic failure seemed to explain his exercise induced symptoms we did not proceed to exercise electrocardiography. Treatment with fludrocortisone, ephedrine, midodrine, propranolol, xamoterol, and the somatostatin analogue, octreotide, resulted in marginal, or no, improvement. Despite the symptoms he continued to play badminton and was in active service as a fireman.

Two years after his first symptom he noted impaired erection and ejaculation, with urinary frequency and nocturia. He passed 
$600 \mathrm{ml}$ of urine by day and $1700 \mathrm{ml}$ at night. Dizziness after exertion gradually worsened, with restricted exercise tolerance. This was followed by dizziness and blurred vision on standing even without preceding exertion. Repeat testing indicated progression of autonomic failure. His blood pressure fell from $145 / 89$ to $80 / 56 \mathrm{~mm} \mathrm{Hg}$ on $45^{\circ}$ head-up tilt as before, but there was no pressor response to mental arithmetic, cutaneous cold, or isometric exercise. He now had a "blocked" Valsalva response with no blood pressure overshoot after breath holding. Sinus arrhythmia was present during deep breathing and heart rate rose when blood pressure fell, indicating a functional cardiac parasympathetic system. The cardiovascular responses to exercise on a bicycle ergometer were assessed supine to exclude the effects of posture on blood pressure. Unlike normal subjects there was no rise in blood pressure during exercise (figure), but there was a large blood pressure fall after exercise. He could barely stand 20 minutes after exercise, and his blood pressure was unrecordable.

In view of his low plasma dopamine $\beta$ hydroxylase concentration, exercise testing was repeated after $1000 \mathrm{mg}$ of 1-threodihydroxyphenylserine (L:DOPS), which bypasses the deficit and can considerably benefit patients with deficiency of this enzyme. ${ }^{6}$ This reduced the postural blood pressure fall before and after exercise (to $95 / 61 \mathrm{~mm} \mathrm{Hg}$ and $70 / 42 \mathrm{~mm} \mathrm{Hg}$ respectively) but his symptoms did not improve either initially or after three days' treatment.

\section{Discussion}

Chronic autonomic failure involves multiple organs, especially the heart and blood vessels. It may be of unknown aetiology (primary) or secondary to disease such as diabetes mellitus. The primary disorders can affect only the autonomic nervous system (pure autonomic failure or idiopathic orthostatic hypotension ${ }^{7}$ ) or occur along with neurological signs (ShyDrager syndrome ${ }^{8}$ ). Impotence and loss of libido are often the first symptoms in men. Disturbances of micturition may occur at an early stage in both sexes, especially in the Shy-Drager syndrome. An inability to sweat may be noticed, particularly in hot countries. The commonest presenting symptom, however, is postural dizziness, or even fainting, on standing erect. This is more noticeable in the mornings, after meals, in a warm environment, and during or after exertion. ${ }^{9}$

Our patient presented with dizziness after, but not during, exertion. He was unusual in having no symptoms of postural hypotension at presentation. The fall in blood pressure after exercise while he was supine provided an explanation. Exercise-induced hypotension in idiopathic orthostatic hypotension was first reported in six patients in $1961^{10}$ and in four others in $1962 .{ }^{11}$ It is assumed that during supine exercise there is vasodilatation in skeletal muscle and that hypotension is secondary to failure of compensatory constriction in other vascular beds. The further fall after exercise in our patient, and we note in three subjects in the original report, ${ }^{10}$ was presumably due to persisting vasodilatation in skeletal muscle with a decrease in venous return when the leg muscle pump stopped. On standing, the venous return and cardiac output probably decreases further and hypotension is accentuated by impaired sympathetic vasoconstriction. Exercise while standing is, therefore, likely to lower blood pressure even further and, as in our patient, this may be more noticeable on stopping exercise. It is not known how to manage this problem. In our case drugs that usually
Blood pressure and heart rate responses: lying and standing before exercise, during exercise (supine), and lying and standing after exercise.

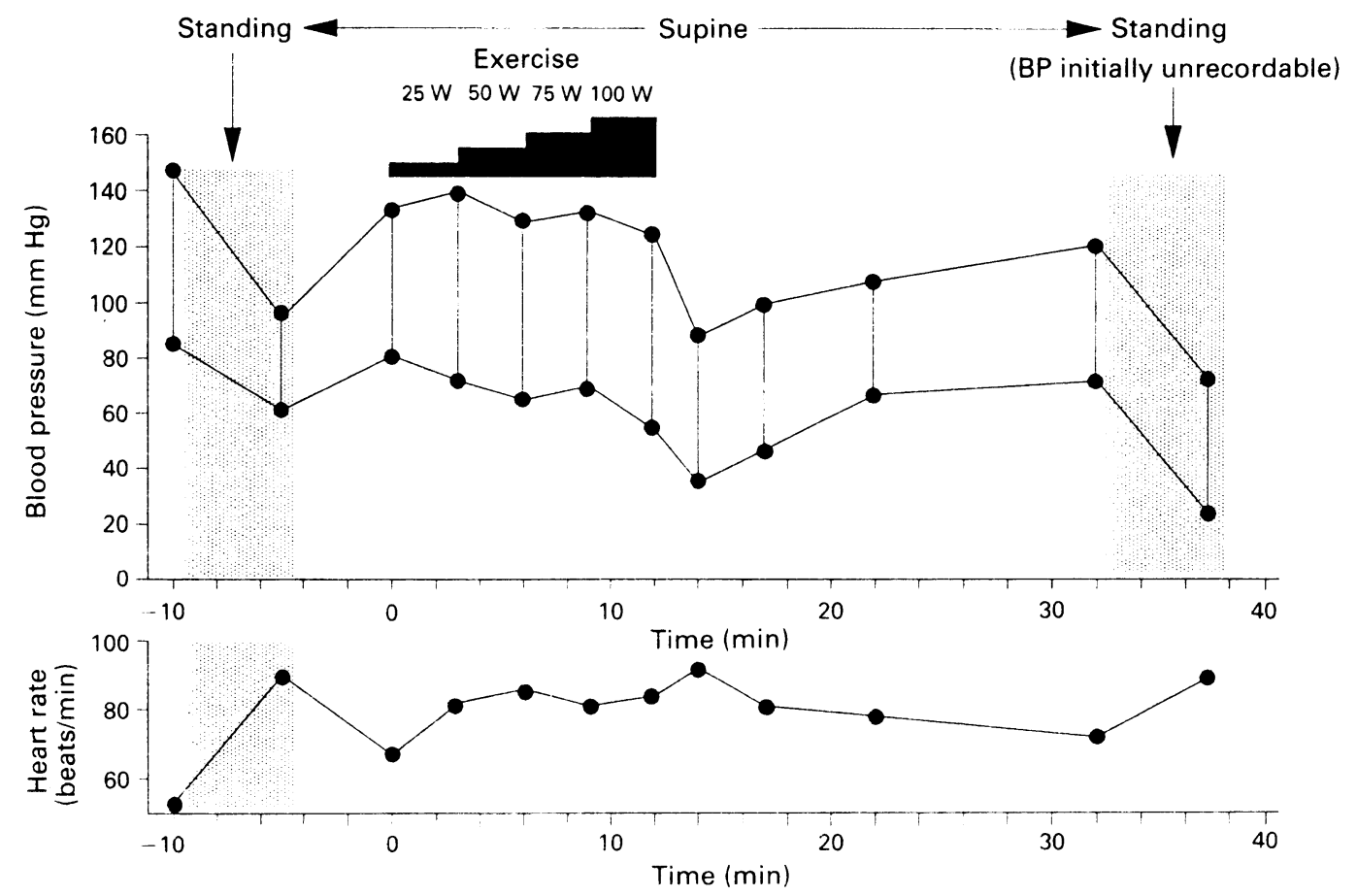


improve postural hypotension were unsuccessful.

In patients with angina and three vessel or left main stem coronary artery disease,,$^{12}$ exercise may cause hypotension; this can be prevented by coronary artery bypass grafting. ${ }^{2}$ Exercise-induced hypotension may also occur in healthy young adults, although rarely. ${ }^{3+}$ In one series 15 subjects were followed up for 2-6 years and remained well with no evidence of cardiac or systemic disease. ${ }^{+}$None underwent formal autonomic testing, but there were no features of autonomic failure. In our patient diagnosis was delayed and a functional component to his symptoms was considered because of his unusual presentation, especially in the face of his ability to play badminton and to continue in active service as a fireman. The possibility of autonomic failure was only considered when the asymptomatic postural fall in blood pressure was noted and hypotension after exercise was recorded.

Autonomic failure, therefore, should be considered in the differential diagnosis of patients presenting with exercise-induced symptoms suggestive of hypotension. Food challenge is of value in the assessment of postprandial and postural hypotension in autonomic failure. ${ }^{5}$ An exercise test incorporating frequent blood pressure recordings, along with formal autonomic tests may be of value, especially in patients with unexplained symptoms during or after exercise.
We thank the Brain Research Trust and the Wellcome Trust for their support.

1 Bruce RA, Cobb LA, Katsura S, Morledge JH, Andrus W, Fuller $\mathrm{T}$. Exertional hypotension in cardiac patients. Circulation 1959;19:543-51.

2 Weiner DA, Macabe CH, Cutler SS, Ryan TJ Decrease in systolic blood pressure during exercise testing: reproducibility, response to coronary by-pass grafting, and ducibility, response to coronary by-pass grafting, and
prognostic significance. Am $\mathcal{F}$ Cardiol 1982;49:1627-32.

prognostic significance. Am f Cardiol 1982;49:1627-32.
3 Eichna LW, Horvath SM, Bean WB. Post exertional

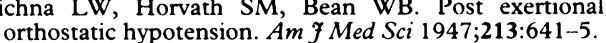

orthostatic hypotension. Am $\mathcal{A}$ Med Sci 1947;213:641-5.
4 Fleg JL, Lakatta EG. Prevalence and significance of postFleg JL, Lakatta EG. Prevalence and significance of post-
exercise hypotension in apparently healthy subjects. $\mathrm{Am}$ f Cardiol 1986;57:1380-4.

5 Mathias CJ, Holly E, Armstrong E, Shareef M, Bannister $R$. The influence of food on postural hypotension in three groups with autonomic failure-clinical and therapeutic implications. $\mathcal{f}$ Neurol Neurosurg Psych 1991; 54:726-30.

6 Mathias CJ, Bannister RB, Cortelli P, Heslop K, Polak $\mathrm{JM}$, Raimbach $\mathrm{S}$, et al. Clinical, autonomic and therapeutic observations in two siblings with postural hypotension and sympathetic failure due to an inability to synthesize noradrenaline from dopamine because of a deficiency of dopamine beta hydroxylase. Quart $\mathcal{F ~ M e d}$ 1990;278:617-33.

7 Bradbury S, Eggleston C. Postural hypotension: a report of three cases. Am Heart f 1925;1:73-86.

8 Shy GM, Drager GA. A neurological syndrome associated with orthostatic hypotension. Arch Neurol 1960;2: 511-27.

9 Bannister R, Mathias CJ. Clinical features and investigation of the primary autonomic failure syndromes. In: $R$ Bannister and CJ Mathias, eds. Autonomic failure. A textbook of clinical disorders of the autonomic nervous system. 3rd Edition. Oxford: Oxford University Press, 1992;531-532.

10 Marshall RJ, Schirger A, Shepherd JT. Blood pressure during supine exercise in idiopathic orthostatic hvpotension. Circulation 1961;24:76--81.

11 Bevegard S, Jonsson B, Karlof I. Circulatory response to recumbent exercise and head-up tilting in patients with disturbed sympathetic cardiovascular control (postural hypotension). Acta Med Scand 1962;172:623-36. 